\title{
Helicobacter pylori eradication in the African setting, with special reference to reinfection and duodenal ulcer recurrence
}

\author{
J A Louw, W Lucke, K Jaskiewicz, A J Lastovica, T A Winter, I N Marks
}

Gastrointestinal Clinic and Department of Medicine, University of Cape Town and Groote Schuur

Hospital, Observatory, South Africa

J A Louw

W Lucke

T A Winter

I N Marks

Department of

Anatomical Pathology,

University of Cape

Town and Groote

Schuur Hospital,

Observatory, South

Africa

K Jaskiewicz

Department of

Microbiology,

University of Cape

Town and Red Cross

War Memorial

Children's Hospital,

Rondebosch,

South Africa

A J Lastovica

Correspondence to

Dr J A Louw, E23

Gastrointestinal Clinic,

Groote Schuur Hospital,

Observatory, South Africa

7925.

Accepted for publication 28 July 1994

\begin{abstract}
The aim of this study was to determine the effect of Helicobacter pylori eradication on the natural history of duodenal ulcer disease, and to determine the incidence of reinfection in adult patients where $H$ pylori had been eradicated in a community with a high prevalence of the infection. An investigator blinded study, with 24 month endoscopic follow up, in subjects where $H$ pylori had been eradicated, and similarly treated subjects where it had not been eradicated was conducted at a tertiary referral hospital. The patients consisted of a volunteer sample of 48 patients with endoscopically proved active duodenal ulcer disease. Duodenal ulcers were healed with omeprazole, $20 \mathrm{mg} /$ day. After endoscopically confirmed healing, patients were treated with either one (17 patients) or two weeks (31 patients) of 'triple therapy'. H pylori status (urease reaction, histological tests, and culture of antral biopsy specimens) was determined at entry, four weeks after the finish of triple therapy and six, 12, and 24 months after this, or whenever an endoscopically proved recurrent duodenal ulcer was found. The main outcome measures were the recurrence of duodenal ulceration, over 24 months in the eradicated and non-eradicated groups and the incidence of reinfection by $H$ pylori in the eradicated group during this follow up period. Five patients in the eradicated group experienced a duodenal ulcer relapse, of which only three were unexplained (1=reinfected, 1 =gastrinoma). Fifteen of 21 patients in the non-eradicated group relapsed over the same period $(p<0.001)$. Only two of 27 patients in the eradicated group were reinfected during the 24 month follow up period. It is concluded that $H$ pylori eradication is an effective treatment strategy for the longterm treatment of duodenal ulcer disease, even in the high prevalence, African setting. Reinfection is uncommon.
\end{abstract}

(Gut 1995; 36: 544-547)

Keywords: Helicobacter pylori, duodenal ulcer disease.

A number of studies have shown that the successful eradication of Helicobacter pylori leads to dramatically reduced duodenal ulcer relapse rates, ${ }^{1-4}$ and $H$ pylori eradication is now an important therapeutic option for the longterm treatment of duodenal ulcer disease. This strategy is considered warranted in all patients in whom medical maintenance or longterm treatment was once recommended.

Limited published data in follow up studies of more than 12 months suggests that the protective effect of $H$ pylori eradication tends to continue for as long as the patient remains uninfected. ${ }^{5}$ The current perception is that the prevalence of $H$ pylori infection in Western society is low and, although age dependent, probably reflects acquisition of the organism in early childhood rather than progressive accrual of the infection - the so called 'cohort-effect'. ${ }^{6}$ The second view may help explain the rarity of $H$ pylori reinfection after successful eradication in developed countries. ${ }^{78}$ Fibreoptic endoscopy has been incriminated as a potential source of $H$ pylori reinfection in such patients. ${ }^{9}$ Reinfection rates of roughly 20 to $27 \%$, however, have been reported in at least two studies, ${ }^{10} 11$ one of which was carried out in a developing country. ${ }^{10}$ Reinfection rates of this magnitude would make it difficult to recommend an eradication strategy even for diseases (such as duodenal ulcer disease) in which $H$ pylori eradication has been shown to be an important benefit.

There is a high prevalence of $H$ pylori in Africa, ${ }^{12} 13$ and the prevalence rate in the Cape Town area is known to be about $60-90 \% .^{14} 15$ This study, in adult duodenal ulcer patients, was undertaken to determine the effect of $H$ pylori eradication in a community with a known high prevalence of the infection.

\section{Methods}

\section{PATIENTS}

Forty eight patients $($ male $=38$, female $=10$ ) with difficult duodenal ulcer disease were studied. Difficult duodenal ulcer disease was defined as patients in whom the duodenal ulcer had not healed after eight weeks of conventional treatment, or as those who had suffered at least one relapse in the 12 months after healing of their index ulcer. All patients were $H$ pylori positive before ulcer healing. All ulcers were healed with omeprazole, $20 \mathrm{mg} /$ day, taken for at least four weeks. Patients were required to give informed consent before entry into the study, and the study protocol was 
approved by the ethics and research committee of the University of Cape Town.

\section{STUDY DESIGN}

\section{Endoscopy schedule}

Patients were endoscoped (Olympus gastroscope using midazolam $2.5 \mathrm{mg}$ intravenously as sedation) at entry, four weeks after the finish of eradication treatment, and six, 12, and 24 months after entry, or whenever dyspepsia recurred.

All endoscopies, with the exception of the initial endoscopy, were done by the same endoscopist. A second endoscopist was required to confirm all ulcer recurrences.

\section{$\mathrm{H}$ pylori status}

$H$ pylori status was determined before healing, a minimum of four weeks after the finish of anti- $H$ pylori treatment, and six, 12 , and 24 months after that, or whenever patients suffered an endoscopically proved duodenal ulcer relapse.

$H$ pylori status was determined from antral biopsy specimens, taken within $5 \mathrm{~cm}$ of the pylorus. Specimens were examined by rapid urease test (one specimen), ${ }^{16}$ histological assessment of specimens stained by the Giemsa method (two specimens), and culture (one specimen). Samples for culture were transported in a jar under microaerophilic conditions (Oxoid Gas Generating BR38, Basingstoke, Hampshire, UK). The specimen was cultured on tryptose blood agar (CM 233; Oxoid Ltd) containing lysed horse blood $(10 \% \mathrm{vol} / \mathrm{vol})$ at $37^{\circ} \mathrm{C}$ under microaerophilic conditions $\left(12 \% \mathrm{CO}_{2}, 88 \%\right.$ air $\left(6 \% \mathrm{O}_{2}\right), 95 \%$ humidity) for a minimum of seven days before being considered negative. $H$ pylori was positively identified by colony morphology and urease reaction (Christensen's urea slope). Patients were considered $H$ pylori positive if the organism was detected with any of these tests.

\section{$\mathrm{H}$ pylori eradication treatment}

All patients were treated with a combination treatment regimen, consisting of a mucosal protective agent (colloidal bismuth subcitrate $120 \mathrm{mg}$ four times daily or sucralfate $1 \mathrm{~g}$ four times daily) metronidazole (400 $\mathrm{mg}$ thrice daily) and a second antibiotic, either tetracycline or amoxicillin ( 250 or $500 \mathrm{mg}$ four times daily depending on body mass). Seventeen patients were treated for one week and 31 received two weeks of treatment.

Compliance was assessed by tablet count at the post-treatment endoscopy visit. The patient's intake of metronidazole, for purposes of this study, was arbitrarily chosen as a marker for overall antibiotic compliance.

\section{Concurrent medication}

No concurrent acid suppressive or other ulcer healing treatment was permitted during the study period.

\section{Statistics}

Categorical data were analysed by means of the $\chi^{2}$ and Fisher's exact test, while continuous variables were analysed by means of the Student $t$ test. A p value of $<0.05$ was considered to be significant.

\section{Results}

Overall, $H$ pylor $i$ infection was eradicated in 27 patients (male $=24$, female $=3$; age mean $(\mathrm{SD})$ $37 \cdot 1(12 \cdot 3)$ years). The infection persisted in the remaining 21 patients (male $=14$, female $=7$; age $37.9(10.6)$ years). Twenty two patients $(81 \%)$ in the eradicated group and $19(90 \%)$ in the non-eradicated group were cigarette smokers $(p=N S)$.

\section{Treatment profile}

Six patients in the eradicated group received one week and 21 received two weeks of combination treatment. In the non-eradicated group, 11 patients received one week, and 10 patients two weeks of treatment $(p<0.05$, one versus two weeks). The average compliance was $89 \%$ in the eradicated group and $86 \%$ in the non-eradicated group.

\section{Duration of follow up}

Three patients in the non-eradicated group were lost to follow up before the six month endoscopy. Of the remaining patients, all 27 of those where $H$ pylor $i$ was initially eradicated have completed their 24 month follow up. Eighteen patients in the non-eradicated group completed either 24 months of follow up, or were withdrawn from the study.

\section{Reinfection of $\mathrm{H}$ pylori}

Of the 27 patients successfully eradicated of the infection, reinfection was reported in two patients: one at the six month visit, and one at the 24 month visit.

\section{$\mathrm{H}$ pylori status and duodenal ulcer relapse} (Table)

In total, five patients who were initially eradicated of the infection relapsed in the 24 month follow up period (five of $27=18 \%$ ). Of these five, only one was reported as having been reinfected, while one patient, with an asymptomatic relapse at the 12 month endoscopy, has a gastrinoma (confirmed by diagnostic gastrin concentrations). There were thus only three (11\%) $H$ pylori negative patients with idiopathic or unexplained relapses - two presenting at 12 months and one at 19 months. The two $H$ pylori negative

$\mathrm{H}$ pylori status and duodenal ulcer relapse

\begin{tabular}{lllc}
\hline Relapsed at & 12 Months & 24 Months & Total \\
\hline H pylori positive group & 14 & 1 & $15^{\star}$ \\
H pylori negative group & $4 \dagger$ & 1 & $5^{\star}$ \\
\hline
\end{tabular}

${ }^{\star} \mathrm{p}<0.001 ;$ fone $=$ reinfected, one $=$ gastrinoma. 
patients who relapsed at 12 months were asymptomatic, and none of the three had more than one confirmed ulcer relapse during the 24 month follow up period. Although suspected, salicylate use could not be confirmed in two of three patients with $H$ pylori negative relapses.

In the non-eradicated group, 15 of 21 patients showed endoscopic evidence of relapse during the 24 month follow up period. This difference in the incidence of relapse between patients where $H$ pylori had been eradicated and those where it had not was highly significant $(\mathrm{p}<0.001$, Fisher's exact test).

\section{Discussion}

This study confirms the finding of previous workers regarding the effect of $H$ pylori eradication in reducing the liability to duodenal ulcer relapse and shows, in addition, that $H$ pylori reinfection after successful eradication is uncommon, even in high prevalence areas. The second finding is in keeping with the low incidence of $H$ pylori reinfection in 'first world' countries $^{2417}$ but are at variance with those of Coelho et al ${ }^{10}$ and Sabbatini et al, ${ }^{11}$ who have reported a $20 \%$ and $27 \%$ reinfection incidence after eradication (maximum follow up of 18 months). These data should be interpreted with caution, however. The experience with omeprazole has taught us that $H$ pylori infection may be difficult to detect, by urease reaction, histological assessment and culture ${ }^{18}$ as well as urea breath test, ${ }^{19}$ if the organism has been suppressed by treatment. It is possible that these apparently high reinfection rates, or at least the early reinfections, may in fact represent the recrudescence of $H$ pylori not eradicated in the first place.

It would be expected that patients where $H$ pylori has been successfully eradicated would escape reinfection only if the exposure risk diminished or, if in the case of exposure, the host had developed the capacity to prevent effective, persistent colonisation of the gastric mucosa. While it has been suggested that $H$ pylori infection is acquired primarily at a very young age in the African setting, ${ }^{20}$ there is no information to show that the exposure risk changes with aging in the 'Third World'; this may be so in the 'First World', however, where it is thought that the risk of being infected by the organism reflects the poorer socioeconomic conditions in a cohort of subjects, a risk that has been diminished by increasing affluence and hence an improvement in living standards. The organism has been found in dental plaque and the saliva in adult patients, ${ }^{2122}$ and there is also some evidence that it can be found in stool, ${ }^{23}$ making oro-oral, faeco-oral transmission, or a combination thereof, the probable vehicle for transmission. While the risk of exposure is therefore unlikely to change in the 'Third World', it is of course possible that the frequency and magnitude of exposure does diminish in adult life. This may be an important factor, as the limited self ingestion studies in previously uninfected subjects show that the infection may establish itself with some difficulty, even in a previously uninfected host with, it is assumed, no acquired immunity. ${ }^{24} 25$ There is indirect evidence that $H$ pylori is acquired at an early age, as a result of household contact, ${ }^{26}$ while adults cohabiting and exposed to daily household contact do not show a similar tendency. ${ }^{27}$

The limited capacity for reinfection may reflect the host's acquired resistance to reinfection by the organism. The possible development, however, of effective acquired immunity to the organism has not been established. This would have profound implications for the development of active immunisation strategies aimed at preventing $H$ pylori associated disease. Resistance to reinfection may, of course, not be the result of acquired immunity in the classic sense. The organism seems to colonise more readily in the presence of suppressed or impaired acid secretion. ${ }^{24}{ }^{25} \mathrm{It}$ is possible that the high colonisation found in young African subjects reflects low acid output, either as a result of an immature acid secretory mechanism or malnutrition, or both. These factors may not be relevant in the adult population, making reinfection less probable.

In conclusion, the outcome of our study suggests that $H$ pylori eradication will be an effective longterm treatment strategy for duodenal ulcer disease, even in developing countries, which tend to have a high incidence of $H$ pylori infection. If confirmed, these findings also augur well for intervention strategies aimed at preventing the other complications of $H$ pylori infection, such as gastric carcinoma.

1 Coghlan JG, Humphries H, Dooley C, Keane C, Gilligan $\mathrm{D}$, McKenna D, et al. Campylobacter pylori and recurrence of duodenal ulcers - a 12-month follow-up study. Lancet 1987; ii: 1109-11.

2 Marshall BJ, Warren JR, Blincow ED, Phillips M, Goodwin CS, Murray R, et al. Prospective double-blind trial of duodenal ulcer relapse after eradication of Campylobacter pylori. Lancet 1988 ; ii: $1437-42$.

3 George LL, Borody TJ, Andrews P, Devine M, MooreJones $\mathrm{D}$, Walton $\mathrm{M}$, et al. Cure of duodenal ulcer after eradication of Helicobacter pylori. Med f Aust 1990; 153: 145-9.

4 Rauws EAJ, Tytgat GNJ. Cure of duodenal ulcer associated with eradication of Helicobacter pylori. Lancet 1990; 335: 1233-5

5 Borody TJ, George LL, Brandl S, Andrews P, Jankiewicz E, Ostopawicz N. Smoking does not contribute to duodenal ulcer relapse after Helicobacter pylori eradication. $\mathrm{Am} \mathcal{f}$ Gastroenterol 1992; 87: 1390-3.

6 Cullen DJ, Collins BJ, Cullen KJ, Christiansen K, Epis J, Surveyor I, et al. A 21 year follow-up of Helicobacter pylori infection - the 'cohort theory' proved. Gut 1992; 33 pylori infection

7 Borody TJ, Cole P, Noonan S, Morgan A, Lenne J, Hyland $\mathrm{L}$, et al. Recurrence of duodenal ulcer and Campylobacter pylori infection after eradication. Med $\mathcal{J}$ Aust 1989; 151: 431-4.

8 Bell GD, Powell KU, Burridge SM, Harrison G, Rameh B, Weil J, et al. Reinfection or recrudescence after apparently successful eradication of Helicobacter pylori infection: implications for treatment of patients with duodenal ulcer disease. Q F Med 1993; 86: 375-82.

9 Langenberg W, Rauws EAJ, Oudbier JH, Tytgat GNJ. Patient-to-patient transmission of Campylobacter pylori infection by fibreoptic gastroduodenoscopy and biopsy. Infection by fibreoptic gis $1990 ; 161: 507-11$.

10 Coelho LGU, Passos MCF, Chausson Y, Sota LM, Maia AF, Brandao MJCC, et al. Duodenal ulcer and eradication of Helicobacter pylori in a developing country. Scand tion of Helicobacter pylori in a deve

11 Sabbatini F, Castiglione F, Piai G, Daniele B, Sapio E, Mazzacca G. The long-term outcome of dyspeptic patients after Helicobacter pylori eradication. Gastroenterology 1993; 104: A182.

12 Holcombe C, Omotara BA, Eldridge J, Jones DM. H pylori, the most common bacterial infection in Africa: a random serological study. Am $\mathcal{F}$ Gastroenterol 1992; 87: 28-30.

13 Glupczynski Y, Bordeaux L, De Prez C, De Vos D, Devreker T, Balegamire B, et al. Prevalence of 
Helicobacter pylori in rural Kivu, eastern Zaire: a prospective endoscopic study. Eur $\mathfrak{f}$ Gastroenterol prospective endoscopic

14 Louw JA, Jaskiewicz K, Girdwood AH, Zak J, Trey G, Lucke W, et al. Helicobacter pylori prevalence in nonulcer dyspepsia - ethnic and socioeconomic differences. $S$ Afr Med F 1993; 83: 169-71.

15 Van Wyk M, Lastovica A, Sinclair-Smith C, Dunn JP, Bornman PC, Louw JA. The prevalence of $H$ pylori in an ethnically diverse, asymptomatic cohort. $S$ Afr Med $\mathcal{f}$ 1993; 83: 784

16 Arvind AS, Cook RS, Tabaqchali S, Farthing MJG. One minute endoscopy room test for Campylobacter pylori. Lancet 1988; i: 704 .

17 Labenz J, Gyenes E, Rühl GH, Bôrsch G. Helicobacter re-infection and clinical course of peptic ulcer disease in the first year post-amoxicillin/omeprazole treatment. the first year post-amoxicillin/omeprazole

18 Louw JA, Zak J, Jaskiewicz K, Lastovica AJ, Kotze TJU, Lucke W, et al. Omperazole may clear but does not eradicate $\mathrm{H}$ pylori. Eur $\mathcal{F}$ Gastroenterol Hepatol 1992; 4: 481-5.

19 Weil J, Bell GD, Powell K, Morden A, Harrison G, Gan PW, et al. Omeprazole and Helicobacter pylori: temporary suppression rather than true eradication. Aliment Pharmacol Ther 1991; 5: 309-13.
20 Holcombe C. Helicobacter pylori: the African enigma. Gut 1992; 33: 429-31.

21 Shames B, Krajden S, Fuska M, Babida C, Penner JL Evidence for the occurrence of the same strain of Campylobacter pylori in the stomach and dental plaque. $\mathcal{f}$ Clin Microbiol 1989; 27: 2849-50.

22 Banatvala N, Romero Lopez C, Owen R, Abdi Y, Davies G, Hardie J, et al. Helicobacter pylori in dental plaque. Lancet 1993; 341: 380.

23 Thomas JE, Gibson GR, Darboe MK, Dale A, Weaver LT. Isolation of Helicobacter pylori from human faeces. Lancet 1992; 340: 1194-5.

24 Morris A, Nicholson G. Ingestion of Campylobacter pylori causes gastritis and raised fasting $\mathrm{pH}$. Am $\mathcal{f}$ Gastroenterol 1987; 82: 192-9.

25 Marshall BJ, Armstrong JA, M Gechie DB, Glancy RJ. Attempt to fulfil Koch's postulates for pyloric Campylobacter. Med f Aust 1985; 142: 436-43.

26 Mendall MA, Goggin PM, Molineaux N, Levy J, Toosy F, Strachan D, et al. Childhood living conditions determine Helicobacter seropositivity in adult life. Gut 1992; 33 (suppl 1): S40.

27 Mendall MA, Goggin PM, Molineaux N, Levi J, Strachan $D$, Northfield TC. The transmission of Helicobacter pylori infection within families. Gut 1993; 34 (suppl 1): 